\title{
Shorter Timed Urine Collection for Detecting Proteinuria in Pre Eclamptic Women
}

\author{
NUSRAT ARA YOUSUF, M. ANWAR HUSSAIN, KHADIJA BEGUM
}

\begin{abstract}
:
Objective: To assess urinary albumin excretion in pre-eclamptic women by shorter timed collection of urine from 12 hours night sample.

Method: This cross sectional study was carried out in the Department of Obstetric and Gynaecology, Bangabandhu Sheikh Mujib Medical University, and Dhaka Medical College Hospital, during the period of November 2004 to February 2005. Among the admitted patient total 40 pregnant women with pre-eclampsia were taken with proper selection criteria. The criteria for selection were hypertension $\left(140 / 90 \mathrm{mmHg}\right.$ or more) after $20^{\text {th }}$ week of gestation and a bed side urine albumin test positive. Detailed medical and obstetric history was taken and thorough examination was done and all the informations were recorded in the pre-designed data collection sheet.
\end{abstract}

Results: The mean \pm SD urinary albumin in 12 hour day, 12 hour night and 24 hour sample were $1.74+0.51 \mathrm{gm} / \mathrm{L}, 1.76+0.51 \mathrm{gm} / \mathrm{L}$ and1.75+0.54 gm/L respectively. Urinary albumin concentration in the 12 hour day \& night samples agreed well with concentration of the 24 hour samples.

Conclusion: From the result it could be concluded that albumin concentrations in the 12hours day and 12-hours night collections were close to the concentrations of the 24-hour collection.

Key Words: Urinary albumin, Pre- eclamptic women.

\section{Introduction:}

Hypertension complicates at least 5-8 percent of all pregnancies ${ }^{1}$. Among the hypertensive disorders of pregnancy the highest risks are associated with preeclampsia and eclampsia ${ }^{2}$. Pre-eclampsia is an important cause of both perinatal and maternal morbidity and mortality ${ }^{3}$. Hypertension is a sign of an underlying pathology which may be pre-existing or appears for the first time during pregnancy 4 . Clinically, pre-eclampsia is characterized by the onset of hypertension, proteinuria and oedema usually beginning in the third trimester ${ }^{5}$.

A small amount of protein $200-300 \mathrm{mg} / 24$ hour is normally excreted in the urine and this amount are probably not increased in pregnancy 6 . A loss of $>300$ $\mathrm{mg} / 24$ hour suggest a disease process ${ }^{7}$. Proteinuria is a late feature but is an important sign of pre-eclampsia and detecting proteinuria is an integral part of the management of hypertensive pregnant women. The presence of proteinuria is required for the diagnosis of pre-eclampsia ${ }^{8,9}$ and is associated with a higher rate of maternal and foetal complication among hypertensive pregnancies ${ }^{10,11}$. Similarly chronic hypertension with superimposed preeclampsia is associated with a higher risk than is stable chronic hypertension during pregnancy ${ }^{12}$. Proteinuria is extremely valuable as a prognostic sign in pre-eclampsia. Frequent monitoring of the amount of protein excreted in the urine must be a part of the evaluation of these patients. A significant increase in proteinuria indicates that the disease has worsened ${ }^{13}$. Weekly estimation of 24 hours protein excretion is the part of management of pre-eclampsia in inpatient care $^{14}$.

The collection of urine over 24 hours however is inconvenient, time consuming and errors due to

1. Jr. Consultant of Obstetrics \& Gynecology. UHC Sulla, Sunamgonj

2. Head of the department of Obstetrics \& Gynecology, BSMMU.

3. $\mathrm{HMO}$ in the department of Obstetrics \& Gynecology, BSMMU. 
incomplete collections and spillage are common. Moreover it is difficult waiting 24 or more hours to know whether proteinuria is truly present ${ }^{15}$.Several authors have advocated shortened timed clearances to alleviate the problems of 24 hours urine collection. Brodows et $\mathrm{al}^{16}$ recommended 3 hours collection. Cook $^{17}$ used overnight collection and Sochett and Odnoman ${ }^{18}$ found 1-hour timed collection satisfactory. This shorter timed urine collection for detecting proteinuria can be tried in pre-eclamptic women.

However for pregnant women, particularly during continuous bed rest in hospital the circadian variation in albumin excretion is smaller or absent and it may therefore be possible to use shorter collection period $^{19}$. A recent study was performed by Helle Kieler with thirty women of preclampsia in Uppsala University Hospital, Sweden, on 2003. He showed that the gold standard of 24 hours urinary excretion for assessment of albuminuria in pre-eclamptic women can be substituted with a 12 hours collection ${ }^{20}$. It will be a great advantage if reliable measurement of protein excretion could be obtained from a shorter collection period.

The most commonly used screening tests for detecting proteinuria is the 'stix' test (Davidson's). It is particularly sensitive for albumin, but has a low sensitivity for other proteins such as globulin and Benzones protein ${ }^{21}$. According to KUO et al. (1992), Dipstick urine analysis cannot be relied on either to detect or to exclude the presence of proteinuria in pregnant women ${ }^{22}$. It has been found that the albumin excretion in urine correlates significantly to the albumin/creatinine ratio during pregnancy ${ }^{23}$.

\section{Materials and method:}

This cross sectional study was carried out in the Department of Obstetric and Gynaecology, Bangabandhu Sheikh Mujib Medical University, and Dhaka Medical College Hospital, during the period of Nov. 04 to Feb. 05. Among the admitted patient total 40 pregnant women with pre-eclampsia was taken with proper selection criteria. The criteria for inclusion were hypertension $\left(140 / 90 \mathrm{mmHg}\right.$ or more) after $20^{\text {th }}$ week of gestation and a bed side urine albumin test positive.

Detailed medical and obstetric history was taken and thorough examination was done and all the information's were recorded in the pre-designed data collection sheet. Before collection of urine all women were carefully instructed about the study and an informed verbal consent was taken. Two clean, dry and graduated plastic containers with $10 \mathrm{ml}$ of toluine as preservatives in each were given to the patient for collection of urine. In one container urine was collected from 8.00 am to $8.00 \mathrm{pm}$ which was called 12 hours day collection. In another container urine was collected from $8.00 \mathrm{pm}$ to the next day $8.00 \mathrm{am}$ which was called 12 hours night collection. Five (5) $\mathrm{ml}$ of urine from 12 hours day and $5 \mathrm{ml}$ of urine from 12 hours night collections were taken in two dry, clean test tubes which was called 12 hours day and night urine samples respectively. Then the urine in the day and night containers were mixed to form a 24 hour urine collection. $5 \mathrm{ml}$ of urine from mixed collection was taken in test tube no.-3 which was called 24 hours urine sample. Three urine samples in three test tubes (test tube no.-I = 12 hours day sample, test tube no. $-2=12$ hours night sample and test tube no. $-3=24$ hours urine sample) were sent to the Biochemistry laboratory of BSMMU for analysis of proteinuria. Mean and median value of each of the urine samples was measured and median differences were calculated. Median difference between 24 hour urinary albumin and 12 hours day and night sample were calculated.

\section{Results:}

Table-I

Age distribution of patients.

\begin{tabular}{lcc}
\hline $\begin{array}{l}\text { Age group } \\
\text { (in years) }\end{array}$ & $\begin{array}{c}\text { Total No. of } \\
\text { patient } n=40\end{array}$ & $\begin{array}{c}\text { Percentage } \\
(\%)\end{array}$ \\
\hline $16-20$ & 10 & 25 \\
$21-25$ & 12 & 30 \\
$26-30$ & 11 & 27 \\
$31-35$ & 6 & 15 \\
$36-40$ & 1 & 2 \\
\hline
\end{tabular}

Table-I shows that $30 \%$ of the patients belong to the age group 21-25 years.

Table-II

Distribution of parity

\begin{tabular}{lcc}
\hline Parity & $\begin{array}{c}\text { No. of patient } \\
\mathrm{n}=40\end{array}$ & $\begin{array}{c}\text { Percentage } \\
(\%)\end{array}$ \\
\hline Primi & 26 & 65 \\
$1-3$ & 10 & 25 \\
$>3$ & 4 & 10 \\
\hline
\end{tabular}


Table-II: $65 \%$ of patients were primigravida, $25 \%$ had two or more children and only $10 \%$ patients had more than 3 children.

Table-III

Gestational age at the time of admission

\begin{tabular}{lcc}
\hline Gestational age & $\begin{array}{c}\text { No. of patient } \\
\mathrm{n}=40\end{array}$ & $\begin{array}{c}\text { Percentage } \\
(\%)\end{array}$ \\
\hline $22-28$ & 10 & 25 \\
$29-35$ & 25 & 62.5 \\
36 or more & 5 & 12.5 \\
\hline
\end{tabular}

Table-III: More than fifty percent (62.5\%) of patients had admitted to hospital with pre-eclampsia at 29-35 weeks of gestation. Mean $\pm S D=30.92 \pm 3.65$ weeks.

Table-IV

Distribution of B.P at the time of admission.

\begin{tabular}{lcc}
\hline B.P on admission & $\begin{array}{c}\text { No. of patient } \\
\mathrm{n}=40\end{array}$ & $\begin{array}{c}\text { Percentage } \\
\text { in } \mathrm{mmHg}\end{array}$ \\
& Mean & SD \\
\hline Systolic & 166.38 & 20.38 \\
Diastolic & 102.88 & 9.93 \\
\hline
\end{tabular}

Table-IV: Mean systolic B.P on admission was 166.38 $\mathrm{mm}$ of $\mathrm{Hg}$. Mean $\pm \mathrm{SD}=166.38 \pm 20.38$. Mean diastolic B.P on admission was $102.88 \mathrm{~mm}$ of $\mathrm{Hg}$. Mean $\pm \mathrm{SD}=$ $102.88+9.93$

\section{Table-V}

Distribution of urinary albumin concentration in three samples.

\begin{tabular}{lcc}
\hline $\begin{array}{l}\text { Number of } \\
\text { patients }(\mathrm{n}=40)\end{array}$ & Mean \pm SD mg/L & Median $\mathrm{mg} / \mathrm{L}$ \\
\hline $\mathrm{A}$ & $1744.90 \pm 513.26$ & 1635 \\
$\mathrm{~B}$ & $1768.35+510.08$ & 1689 \\
$\mathrm{C}$ & $1757.63 \pm 549.92$ & 1640 \\
\hline
\end{tabular}

Table- $\mathrm{V}$ : $\mathrm{A}=$ Urinary albumin concentration in 12 hour day sample (mg/L)

$\mathrm{B}=$ Urinary albumin concentration in 12 hour night sample (mg/L)

$\mathrm{C}=$ Urinary albumin concentration in 24 hour sample $\mathrm{mg} / \mathrm{L}$.

Table shows that mean urinary albumin in 12 hour day sample was $1744.90 \mathrm{mg} / \mathrm{L}$. Mean+SD= $1744.90 \pm 513.26 \mathrm{mg} / \mathrm{L}=1.74+0.51 \mathrm{gm} / \mathrm{L}$ Mean urinary albumin concentration in 12 hour night sample was $1768.35 \mathrm{mg} / \mathrm{L}$. Mean \pm SD $=1768.35+510.08 \mathrm{mg} / \mathrm{L}$ $=1.76+0.51 \mathrm{gm} / \mathrm{L}$. Mean urinary albumin concentration in 24 hour sample was $1757.63 \mathrm{mg} \mathrm{L}$. Mean \pm SD $=1757.63+549.92 \mathrm{mg} / \mathrm{L}=1.75+0.54$ $\mathrm{gm} / \mathrm{L}$ Mean 24 hour urine volume was $1.9 \mathrm{~L}$ (SD 0.59 L) and median 1.8L (Range IL to 3.4L) Urinary albumin concentration in the 12 hour day \& night samples agreed well with concentration of the 24 hour samples.

\section{Table-VI}

Median difference of albumin concentration in three samples.

\begin{tabular}{lc}
\hline Number of patient $n=40$ & Median difference \\
\hline C-A & $10 \mathrm{mg} / \mathrm{L}$ \\
C-B & $-7.5 \mathrm{mg} / \mathrm{L}$ \\
A-B & $-20 \mathrm{mg} / \mathrm{L}$ \\
\hline
\end{tabular}

Table-VI: shows that the median difference between the 24 hours and 12 hours day collection was $10 \mathrm{mg} /$ $\mathrm{L}$ (Range -373 to 470 ). The median differences between the 24 hours and night collection was -7.5 $\mathrm{mg} / \mathrm{L}$ (Range -411 to $319 \mathrm{mg} / \mathrm{L}$ ). The median difference between 12 hours day and 12 hours night collection was -20 mg/L (range -309 to $350 \mathrm{mg} / \mathrm{L}$ ).

\section{Table-VII}

Comparison of urinary albumin excretion in the different samples.

\begin{tabular}{ll}
\hline Number of patient $n=40$ & $P$ Value $^{3}$ \\
\hline Group A vs. B & $>0.10^{\mathrm{ns}}$ \\
Group A vs. C & $>0.50^{\mathrm{ns}}$ \\
Group B vs. C & $>0.50^{\mathrm{ns}}$ \\
\hline
\end{tabular}

Table-VII shows that when paired students' ' $\mathrm{t}$ ' test was applied; the differences between the urinary albumin concentrations in three different samples were statistically not significant.

\section{Discussion:}

Pre-eclampsia is a serious complication of pregnancy and is responsible for significant morbidity and mortality in the foetus, the newborn and mother. It is important to detect the condition as early as possible. Albuminuria is an important sign of pre-eclampsia and repeated urine analysis to screen for the condition is part of the standard antenatal care; detecting proteinuria in pregnant women is usually 
done by routine visual dipstick urinalysis. However recent studies have documented inaccuracies of this method, giving high false positive and false negative results, when compared with the gold standard of 24 hour urine measurement.

When pre-eclampsia with persistent albuminuria develops, urinary albumin excretion is monitored by frequent 24 hour urine samples. The purpose of this surveillance was that increased albumin excretion is a sign of aggravation of pre-eclampsia and reflects serious nephropathy; massive albumin excretion may result in planned preterm delivery. Obtaining a complete 24 hour urine collection is difficult, inconvenient, time consuming and errors due to incomplete collections and spillage are common. In the present study, we have tried to overcome the difficulties of 24 hour urine collection by a shorter timed collection period.

In this study, in women with pre-eclampsia who had significant albuminuria, we found good agreement between urinary albumin concentrations measured in samples collected for 12 hours and the traditional 24 hours collection. This is in accordance with the observation made by the Dr. Helle Kieler et al (January 2003) in a prospective study in the Department of women's and children's health, Obstetric and Gynaecology, Uppsala University Hospital, Sweden. He measured urinary albumin excretion in 30 women with pre-eclampsia. He concluded that the gold standard of 24-hour urinary excretion for assessment of albuminuria in pre-eclamptic women could be substituted with a 12-hour collection. He also observed that spot urine samples were inaccurate and is therefore not recommended for quantification of albumin excretion. He showed that the median difference between the 24 hour and 12 hour day urinary albumin excretion was $-3 \mathrm{mg} / \mathrm{L}$ which was $10 \mathrm{mg} / \mathrm{L}$, in our study and the median difference between the 24 hour and 12 hours night urinary albumin excretion was $17 \mathrm{mg} / \mathrm{L}$ which was $-7.5 \mathrm{mg} / \mathrm{L}$ in our study.

Our study showed that the agreement between albumin concentration in 24 hour and 12 hour night sample was slightly better than that of the 12 hour day sample (-5.7 mg/L vs. $10 \mathrm{mg} / \mathrm{L})(17 \mathrm{mg} / \mathrm{L}$ vs. -3 $\mathrm{mg} / \mathrm{L}$ in previous study). Median difference in night sample over estimate the albumin concentration as indicated by the negative values for mean and median differences. Over estimation of albumin excretion may lead to interventions such as planned preterm delivery to be performed earlier than required. Under estimation of albumin excretion however, may delay detection of severe nephropathy resulting in damage to the kidney. Urinary albumin excretion is at least in diabetic patients known to have day to day variability; presumably, the same is true in pre-eclampsia. However, there is little likelihood that this biologic variability influences the results as all samples were collected within 24 hours period.

In some studies urinary albumin/creatinine ratio is a valid estimate of albumin excretion rate. But other studies found that adding analysis of creatinine is of limited use and only increases the costs. As the increase in albumin excretion in severe pre--eclampsia, occurs rapidly and suddenly, frequent urine analysis are required. This analysis should be valid and easy to perform and should be as inexpensive as possible; a night sample collection starting at $8.00 \mathrm{pm}$ and ending at $8.00 \mathrm{am}$ is thought to be acceptable to women than a 24 hour collection. A shorter period should reduce the risk of incomplete collection.

\section{Conclusion:}

In the present study we have observed that the difference between the urinary albumin excretion in 24 hour sample and 12 hour day and 12 hour night sample was statistically insignificant. This finding suggested that the 24-hour urinary excretion for assessment of albuminuria in pre-eclamptic women may be substituted with a 12-hour night collection. Further study with a large number of patients is necessary to determine whether 12-hour urinary albumin excretion can be used for quantification of albuminuria in pre-eclamptic women.

\section{References:}

1. Hoque MM, Bulul T, Mahal M, Islam NAF and Ferdousi $M$, Serum Homocysteine in preeclampsia \& eclampsia, Bangladesh Medical Research Council Bulletine, 2008; 34: 1620.

2. Decherney AH, Nathan L, Goodwin TM, Laufer N. Current Diagnosis \& Treatment - obstetrics and Gynaecology. Hypertension in pregnancy, $10^{\text {th }}$ edition. McGraw-Hill; 2012: P-318-326.

3. Taufield P.A., Ales K.L., Resnick L.M., Druzin M.L., Gertner, J.M. and Laragh J.H: Hypocalciuria in pre-eclampsia. N Engl J Med, 1987; 316:715-8.

4. Dutta D.C: Editor Textbook of obstetrics including perinatology and contraceptions, $6^{\text {th }}$ edition, 
New central book agency (p) Ltd. India, 2005; p-221.

5. Paternoster DM, Fantinato $S$, Manganelli F, Nicolini U, Milani M, Ginolami A: Recent progress in the therapeutic management of preeclampsia. Expert opin. Pharmacother. 2004 Nov; (11): 2233-9.

6. Wright A, Stule P, Bennet J.R. Watts $G$ and Plak A. Urinary excretion of albumin in normal pregnancy. Br J obstet Gynecol, 1987; 94: 408-412.

7. Alan H, Erncy D. Current obstetrics and gynaecologic diagnosis and treatment, $9^{\text {th }}$ edition. McGraw-Hill; 2004: P- 338.

8. Davey DA, MacGillivray I. Classification and definition of the hypertensive disorders of pregnancy. Am J obstet Gynecol 1988; 158: 892-898 .

9. National high blood pressure education program working group. Report on high blood pressure in pregnancy. Am J obstet gynecol 1990; 163: 1691- 1712 .

10. Ferrazanis, Caruso A, D'c carolis S, Martino IV, Mancuso S, Proteinuria and outcome of 444 pregnancies complicated by hypertension. Am J Obstet gynecol 1990; 162: 366- 371.

11. Brown Ma, Buddie ML. Importance of nonproteinuric hypertension in pregnancy. Hypertens pregnancy, 1995; 14: 57- 65.

12. Mabie W.C. and Sibai B.M: Hypertensive states of pregnancy, 1994; 380- 381.

13. Fernando A. Practical Guide to High-Risk Pregnancy and Delivery, $2^{\text {nd }}$ edition. Mosby; 1984: P-189.

14. Edmonds DK. Dewhurst's textbook of obstetrics and Gynaecology for postgraduates, $6^{\text {th }}$ edition, 1999 Blackwell Pubs Ltd. P-172.
15. S.W. Lindow, D.A. Davey. The variability of urinary protein and creatinine excretion in patients with gestational proteinuric hypertension. Br. J Obstet Gynecol 1992; 99: 869-872.

16. Brodows R.G, Nichols D, Shaker G, Kubasik N. Evolution of a new radioimmunoassay for urinary albumin. Diabetes care 1986; 9: 189-93.

17. Cook J, Daneman D. Overnight VS. 24 hour urine collection in detection of microalbuminuria. Diabetes care 1990; 13: 813.

18. Sochette E. Daneman D. Screening tests to detect microalbuminuria in children with diabetes. J Pediatr 1988; 112:744-48.

19. Doumen CE, Van der post JA, Van Acker BA, Boer K, Koopman MG. Circadian variation of urinary albumin excretion in pregnancy. $\mathrm{Br} \mathrm{J}$ obstet Gynecol 1995; 102(2): 107-110.

20. Helle Kieler, Tuttan Zettergnen, Hanna Svensson, Paul W. Diekman. Assessing urinary albumin excretion in pre-eclamptic women: Which simple to use? BJOG, 2003; 110: 12-17.

21. Christopher RW Edwards. Davidson's principles and practice of medicine. 17th edition. Churchill Living Stone; 1995: P-621.

22. KUO S.V, Koumantakis G and Gallery E. Proteinuria and its assessment in normal and hypertensive pregnancy. American J. Obst. Gynaecol, 1992; 167(3): 723-728.

23. Risberg A, Larsson A, Olssonk, Lyrenas $S$, Sjoquist M. Relationship between urinary albumin and albumin/creatinine ratio during normal pregnancy and pre-eclampsia. Scand J Clin Lab invest. 2004; 64: 17-23. 